\title{
Achieving Enhanced Thermoelectric Performance in Multiphase
}

\section{Materials}

Ning Jia, ${ }^{a, \#}$ Xian Yi Tan, ${ }^{a, b, \#}$ Jianwei Xu, ${ }^{, *}$ Qingyu Yan, ${ }^{a,{ }^{*}}$ and Mercouri G. Kanatzidis ${ }^{c, *}$

${ }^{a}$ School of Materials Science and Engineering, Nanyang Technological University, Singapore 639798.

${ }^{b}$ Institute of Materials Research and Engineering, \#08-03, 2 Fusionopolis Way, Agency

for Science, Technology and Research, Singapore 138634.

c Department of Chemistry, Northwestern University, Evanston, Illinois 60208, United States

\# Equal contribution: Ning Jia and Xian Yi Tan contributed equally to this work.

*Corresponding authors: jw-xu@imre.a-star.edu.sg; alexyan@ntu.edu.sg; m-kanatzidis@northwestern.edu. 


\section{Contents}

\section{Table S1-S3}

Table S1. A summary table of references for the state-of-the-art TE material discussed in the Figure 1b.

Table S2. A summary table of references for the different strategies and perspectives of reviews discussed in the Introduction.

Table S3. A summary table of references for the different strategies and perspectives of reviews discussed in our published examples.

Table S4: Summary of $Z T_{\text {peak }}$ values and their corresponding temperatures $(T)$, as well as $Z T_{\text {avg }}$ values and their corresponding temperature ranges $\left(T_{\mathrm{C}}-T_{\mathrm{H}}\right)$, of recently reported $\mathrm{PbTe}$-based materials. Results from our work are highlighted for comparison.

2. Material science of designing a good thermoelectric material

\section{General Synthetic Processes and Guidelines for Multiphase TE materials}

\section{References}


Table S1. A summary table of references for the state-of-the-art TE material discussed in the Figure $1 b$.

\begin{tabular}{|c|c|}
\hline Material & References \\
\hline $\mathrm{Bi}_{2} \mathrm{Te}_{3}$ & $1-4$ \\
\hline $\mathrm{PbTe}$ & $5-9$ \\
\hline Skutterudites & $10-14$ \\
\hline $\mathrm{Mg}_{2}(\mathrm{Si}, \mathrm{Sn}, \mathrm{Ge})$ & $15-17$ \\
\hline half-Heusler & $18-20$ \\
\hline $\mathrm{SiGe}$ & $2,21-22$ \\
\hline $\mathrm{SnSe}$ & $23-24$ \\
\hline $\mathrm{Cu}_{2} \mathrm{Se}$ & $25-27$ \\
\hline Zintl phases & $28-29$ \\
\hline GeTe & $30-33$ \\
\hline $\mathrm{SnTe}$ & $34-37$ \\
\hline $\mathrm{Sb}_{2} \mathrm{Si}_{2} \mathrm{Te}_{6}$ & $38-39$ \\
\hline $\mathrm{Te}$ & 40 \\
\hline
\end{tabular}

Table S2. A summary table of references for the different strategies and perspectives of reviews discussed in the Introduction.

\begin{tabular}{|c|c|}
\hline Strategies and perspectives & References \\
\hline Chemical Bonding & 41 \\
\hline Phonon Transport Manipulation & 42 \\
\hline Nanostructuring & $43-45$ \\
\hline Band Manipulation & 46 \\
\hline Point Defects & $47-48$ \\
\hline Deep Level Defects & $49-50$ \\
\hline Wide-Bandgap Semiconductors & 51 \\
\hline Practical Applications & $52-54$ \\
\hline
\end{tabular}


Table S3. A summary table of references for the different strategies and perspectives of reviews discussed in our published examples.

\begin{tabular}{|c|c|c|}
\hline Strategies and perspectives & Applicable Sub-sections & References \\
\hline Chemical Bonding & $2.2,4.2$ & 41 \\
\hline Phonon Transport & $2.1,3.3,4.1$ & 42 \\
Manipulation & $2.1,2.2,3.1,3.3,4.2$ & $43-45$ \\
\hline Nanostructuring & $2.1,2.2,3.1,4.1,4.2$ & 46 \\
\hline Band Manipulation & $3.2,3.3$ & $47-48$ \\
\hline Point Defects & 2.1 & 51 \\
\hline Deep Level Defects & 3.3 & $52-54$ \\
\hline Wide-Bandgap & & 50 \\
\hline Semiconductors & & \\
\hline Practical Applications & & \\
\hline
\end{tabular}


Table S4: Summary of $Z T_{\text {peak }}$ values and their corresponding temperatures $(T)$, as well as $Z T_{\text {avg }}$ values and their corresponding temperature ranges $\left(T_{\mathrm{C}}-T_{\mathrm{H}}\right)$, of recently reported $\mathrm{PbTe}$-based materials. Results from our work are highlighted for comparison.

\begin{tabular}{|c|c|c|c|c|}
\hline Type & Material & $Z T_{\text {peak }[\mathrm{T}]}$ & $Z T_{\text {avg [Tc-TH] }}$ & Ref. \\
\hline $\mathrm{n}$ & $\mathrm{Pb}_{0.988} \mathrm{Sb}_{0.012} \mathrm{Te}-13 \% \mathrm{GeTe}$ & $1.38_{[623 \mathrm{~K}]}$ & $1.04_{[300-773 \mathrm{~K}]}$ & 55 \\
\hline $\mathrm{n}$ & $\mathrm{Pb}_{0.98} \mathrm{Ga}_{0.02} \mathrm{Te}-5 \% \mathrm{GeTe}$ & $1.47[673 \mathrm{~K}]$ & $1.27[400-700 \mathrm{~K}]$ & 56 \\
\hline $\mathrm{n}$ & $\mathrm{Pb}_{0.999} \mathrm{Ti}_{0.001} \mathrm{Te}$ & $1.20_{[773 \mathrm{~K}]}$ & $0.69[300-773 \mathrm{~K}]$ & 57 \\
\hline $\mathrm{n}$ & $\mathrm{PbTe}_{0.996} \mathrm{I}_{0.004}-1 \% \mathrm{MgTe}$ & $1.20_{[700 \mathrm{~K}]}$ & $0.80_{[300-873 \mathrm{~K}]}$ & 58 \\
\hline $\mathrm{n}$ & $\mathrm{Pb}_{0.98} \mathrm{In}_{0.02} \mathrm{Te}_{0.8} \mathrm{~S}_{0.2}$ & $1.10_{[673 \mathrm{~K}]}$ & $0.87_{[300-773 \mathrm{~K}]}$ & 59 \\
\hline $\mathrm{n}$ & $\left(\mathrm{Pb}_{0.93} \mathrm{Sn}_{0.07}\right)\left(\mathrm{Te}_{0.93} \mathrm{Se}_{0.07}\right)$ & $1.40[773 \mathrm{~K}]$ & $0.97[423-873 \mathrm{~K}]$ & 60 \\
\hline $\mathrm{n}$ & $\mathrm{Pb}_{0.985} \mathrm{Sb}_{0.015} \mathrm{Te}$ & $1.00[773 \mathrm{~K}]$ & $0.60_{[300-873 \mathrm{~K}]}$ & 61 \\
\hline $\mathrm{n}$ & $\mathrm{Pb}_{0.98} \mathrm{In}_{0.005} \mathrm{Sb}_{0.015} \mathrm{Te}_{0.94} \mathrm{~S}_{0.06}$ & $1.40_{[773 \mathrm{~K}]}$ & $0.87[300-873 \mathrm{~K}]$ & 61 \\
\hline $\mathrm{n}$ & $\mathrm{PbTe}-4 \% \mathrm{InSb}$ & $1.83_{[773 \mathrm{~K}]}$ & $1.0_{[300-723 \mathrm{~K}]}$ & 62 \\
\hline $\mathrm{n}$ & $\mathrm{Cu}_{3.3} \mathrm{~Pb}_{100} \mathrm{Sb}_{3} \mathrm{Te}_{100} \mathrm{Se}_{6}$ & $1.40_{[723 \mathrm{~K}]}$ & $0.94_{[300-723 \mathrm{~K}]}$ & 63 \\
\hline $\mathrm{n}$ & $\mathrm{Pb}_{0.9875} \mathrm{Sb}_{0.0125} \mathrm{Te}_{0.88} \mathrm{~S}_{0.12}$ & $1.40[900 \mathrm{~K}]$ & $0.71_{[300-773 \mathrm{~K}]}$ & 64 \\
\hline $\mathrm{n}$ & $\mathrm{Cu}_{0.0045} \mathrm{PbTe}_{0.75} \mathrm{Se}_{0.25}$ & $1.60[750 \mathrm{~K}]$ & $1.07[400-850 \mathrm{~K}]$ & 65 \\
\hline $\mathrm{p}$ & $(\mathrm{PbTe})_{0.6}(\mathrm{PbSe})_{0.4}$ & $1.90_{[873 \mathrm{~K}]}$ & $0.94_{[300-873 \mathrm{~K}]}$ & 66 \\
\hline $\mathrm{p}$ & $\mathrm{PbTe}_{0.85} \mathrm{Se}_{0.15}-2 \% \mathrm{Na}-4 \% \mathrm{SrTe}$ & $2.30[923 \mathrm{~K}]$ & $1.23[300-873 \mathrm{~K}]$ & 67 \\
\hline $\mathrm{p}$ & $\mathrm{Pb}_{0.98} \mathrm{Na}_{0.02} \mathrm{Te}-8 \% \mathrm{SrTe}$ & $2.50[923 \mathrm{~K}]$ & $1.67[300-900 \mathrm{~K}]$ & 8 \\
\hline $\mathrm{p}$ & $\mathrm{Na}_{0.03} \mathrm{Eu}_{0.03} \mathrm{Cd}_{0.03} \mathrm{~Pb}_{0.91} \mathrm{Te}$ & $2.50_{[850 \mathrm{~K}]}$ & $1.38_{[300-850 \mathrm{~K}]}$ & 68 \\
\hline
\end{tabular}




\section{Material science of designing a good thermoelectric material \\ (i) Electronegativity differences and carrier mobility}

As a rough guideline for exploring new TE materials, the average electronegativity difference of the constituent elements should be $\leq 0.5 .{ }^{69}$ This is to limit the charge transfer between the cations and anions and to ensure that their interacting orbitals are in a similar energy range for more efficient overlap, which will result in sharper bands in the E-k dispersion curve and the electronic band structure. ${ }^{41}$ For the inertial carrier

effective mass, $m_{I}^{*}=\frac{\hbar^{2}}{d^{2} E / d k^{2}}$, implying that a sharper curvature in the E-k dispersion curve will reduce $m_{I}^{*}$, leading to higher charge carrier mobilities.

\section{(ii) Crystal symmetry and orbital character tuning for band engineering}

For multiple bands to be utilized for electronic transport, the edges of the other bands must be close in energy $(\leq 0.1 \mathrm{eV})$ to the valence band maximum (VBM, for p-type materials) or conduction band minimum (CBM, for n-type materials). Such bands are considered degenerate and can be quantified by the effective band degeneracy or multiplicity $\left(\mathrm{N}_{\mathrm{V}}{ }^{*}\right)$. As Seebeck coefficient $(S)$ and electrical conductivity $(\sigma)$ have opposing correlations to $m_{I}^{*}$, where lower $m_{I}^{*}$ is beneficial to $\sigma$ but deleterious to $S$, a higher $\mathrm{N}_{\mathrm{V}}$ * can improve $S$ with small compromises to $\sigma$, leading to an increased power factor $(\mathrm{PF}) .^{70}$

Materials with highly symmetric crystal structures (eg. cubic PbTe or hexagonal $\mathrm{Bi}_{2} \mathrm{Te}_{3}$ ) have naturally high $\mathrm{N}_{\mathrm{V}}$ * values when their VBM or CBM lie on or between high symmetry lines on the Brillouin zone, as there are effectively many symmetrically identical duplicates of such bands. $\mathrm{N}_{\mathrm{V}}$ * can also be increased by doping to tune the lattice parameters to improve the crystal symmetry, such that the non-degenerate bands are shifted to be closer in energy to the VBM or CBM, as in the case where $\mathrm{Ag}_{\mathrm{Cu}}$ or $\mathrm{Ga}_{\text {In }}$ substitutional point defects were used to transform the distorted tetragonal chalcopyrite $\mathrm{CuInTe}_{2}$ into a pseudo-cubic lattice. ${ }^{71}$ For materials like PbTe and SnTe, where the $L$ band valence band is higher than the adjacent $\Sigma$ band, due to the 
stereochemically quenched cation $\mathrm{s}^{2}$ lone pair orbital character of the $L$ band. Therefore, progressive substitution of the $\mathrm{Pb}^{2+}$ or $\mathrm{Sn}^{2+}$ cations with other Group 2 or transition metal divalent cations can lower the energy of the $L$ band by reducing its s-orbital character, due to the absence of $\mathrm{s}^{2}$ lone pair orbitals in these divalent dopant cations. ${ }^{72-}$ 73 The energy level of the adjacent $\Sigma$ band, which is dominated by anionic p-orbital character instead of cationic s-orbital character, remains relatively unaffected. Therefore, the $L$ band can be brought closer in energy to the $\Sigma$ band through the tuning of orbital character. Bringing of the adjacent bands to be closer to degeneracy is termed as "band convergence".

\section{(iii) Microstructural defects for lattice thermal conductivity reduction}

Microstructural defects scatter phonons by reducing their relaxation times, which will lower the lattice thermal conductivity. However, thermal transport through the lattice occurs thorough the propagation of phonons at varying frequencies. At low temperatures, lattice thermal conduction mainly occurs through low frequency phonons as the available thermal energy may be insufficient to excite the higher frequency phonons. At high temperatures, the energy is enough to excite the high frequency phonons, causing them to dominate the thermal transport. Zero-dimensional (0D) point defects (vacancies, substitutional atomic defects, antisite defects, discordant atoms) mainly scatter high-frequency phonons. One-dimensional (1D) defects like dislocations can scatter mid-frequency phonons, while 2D interface defects (grain boundaries and interfaces with secondary phases) predominantly scatter low-frequency phonons. ${ }^{42,} 48$ Therefore, a TE material that is designed to have all of these defects can effectively scatter phonons across a wide range of frequencies, leading to low lattice thermal conductivities over a wide temperature range and improving the $Z T_{a v g}$.

\section{General Synthetic Processes and Guidelines for Multiphase TE materials}

In many of our engineered polycrystalline multiphase TE materials, typical synthesis procedures involve heating the constituent elements above the melting point of the highest melting element or that of the targeted compound, followed by annealing the 
melted ingot at a much lower temperature. As a general rule of thumb, dopant elements with lower electronegativities will form stronger bonds with the more electronegative chalcogen and will be more likely to precipitate out as binary chalcogenide secondary phases. Upon melting, the elements are usually uniformly mixed due to the fast diffusion rate of atoms in liquid form and the higher solubility of the dopant atoms in the matrix at higher temperatures. A rapid cooling rate, usually achieved by quenching the molten liquid mixture in ice water, can be used to retain this uniformly mixed state at room temperature, following by a annealing process at some temperature depending on the material for few hours to equilibrate the sample. Whereas a slower cooling rate will provide more time for the dopants to form larger precipitates. Through the addition of dopant elements that have the potential to form secondary phases, as well as finetuning the heat treatment process (according to phase diagrams if available), the nanoprecipitates' formation and distribution can be optimized for TE performance and even mechanical property enhancement. While these melt-annealing synthesis methods incorporate traditional metallurgical concepts and techniques, they differ from the synthesis of traditional TE materials by zone melting to produce large-grained or singlecrystalline ingots. They also differ from other common techniques used to incorporate secondary phases through the mixing of the matrix material with the additive by ball milling followed by the consolidation process. While the melt-annealing technique may be harder to control the formation and distribution of secondary phases, but if successful, the precipitates are more likely to form coherent interfaces with the matrix as compared to high angle grain boundaries, ${ }^{74}$ as the dopant elements were nucleated from within the matrix from very high temperatures, rather than added externally with mechanical agitation. The ingots from the heat treatment process were usually pulverized into powder before consolidation by spark plasma sintering at a temperature that is $\sim 70 \%$ of the compound's melting or decomposition point. ${ }^{75}$ As this section mainly discusses the general approach used to synthesize the engineered multiphase TE materials, where the exact details of the synthetic process varies for the different materials, interested readers are highly encouraged to find the strategies for the cited references in the main paper, or check out other comprehensive review papers on synthesis and processing 
techniques for TE materials. ${ }^{75-77}$

Nevertheless, such methods are not applicable to the bulk preparation of polycrystalline $\mathrm{Sb}_{2} \mathrm{Si}_{2} \mathrm{Te}_{6}$, due to the high melting point of $\mathrm{Si}\left(1,414{ }^{\circ} \mathrm{C}\right)$ and the low decomposition temperature of $\mathrm{Sb}_{2} \mathrm{Si}_{2} \mathrm{Te}_{6}\left(650{ }^{\circ} \mathrm{C}\right)$. As the constituent elements of $\mathrm{Sb}_{2} \mathrm{Si}_{2} \mathrm{Te}_{6}$ are unable to undergo melting to form homogeneous mixtures, the mixing must first be performed by a ball milling step. The ball milling step will also reduce the particle size of the starting Si wafer flakes, in order to enhance its reactivity in the following solid-state reaction step, by annealing the powder mixture at $550{ }^{\circ} \mathrm{C}$. Contrary to the other multiphase materials highlighted in this paper, the secondary phase formation occurs during the sintering step, where the $\mathrm{Si}_{2} \mathrm{Te}_{3}$ nanosheets form by the in-situ decomposition of $\mathrm{Sb}_{2} \mathrm{Si}_{2} \mathrm{Te}_{6}$ in molten excess Te on the grain boundaries. ${ }^{38}$

\section{References:}

(1) Goldsmid, H. J.; Douglas, R. W., The use of semiconductors in thermoelectric refrigeration. J. Appl. Phys. 1954, 5 (11), 386-390.

(2) Yang, J.; Xi, L.; Qiu, W.; Wu, L.; Shi, X.; Chen, L.; Yang, J.; Zhang, W.; Uher, C.; Singh, D. J., On the tuning of electrical and thermal transport in thermoelectrics: an integrated theory-experiment perspective. Npj Comput. Mater. 2016, 2 (1), 15015.

(3) Poudel, B.; Hao, Q.; Ma, Y.; Lan, Y.; Minnich, A.; Yu, B.; Yan, X.; Wang, D.; Muto, A.; Vashaee, D.; Chen, X.; Liu, J.; Dresselhaus, M. S.; Chen, G.; Ren, Z., HighThermoelectric Performance of Nanostructured Bismuth Antimony Telluride Bulk Alloys. Science 2008, 320 (5876), 634.

(4) Kim, S. I.; Lee, K. H.; Mun, H. A.; Kim, H. S.; Hwang, S. W.; Roh, J. W.; Yang, D. J.; Shin, W. H.; Li, X. S.; Lee, Y. H.; Snyder, G. J.; Kim, S. W., Dense dislocation arrays embedded in grain boundaries for high-performance bulk thermoelectrics. Science 2015, 348 (6230), 109.

(5) Bell, L. E., Cooling, Heating, Generating Power, and Recovering Waste Heat with Thermoelectric Systems. Science 2008, 321 (5895), 1457.

(6) Pei, Y.; Shi, X.; LaLonde, A.; Wang, H.; Chen, L.; Snyder, G. J., Convergence of electronic bands for high performance bulk thermoelectrics. Nature 2011, 473 (7345), 66-69.

(7) Biswas, K.; He, J.; Blum, I. D.; Wu, C.-I.; Hogan, T. P.; Seidman, D. N.; Dravid, V. P.; Kanatzidis, M. G., High-performance bulk thermoelectrics with all-scale hierarchical architectures. Nature 2012, 489 (7416), 414-418.

(8) Tan, G.; Shi, F.; Hao, S.; Zhao, L.-D.; Chi, H.; Zhang, X.; Uher, C.; Wolverton, 
C.; Dravid, V. P.; Kanatzidis, M. G., Non-equilibrium processing leads to record high thermoelectric figure of merit in PbTe-SrTe. Nat. Commun. 2016, 7 (1), 12167.

(9) Zhu, T.; Liu, Y.; Fu, C.; Heremans, J. P.; Snyder, J. G.; Zhao, X., Compromise and Synergy in High-Efficiency Thermoelectric Materials. Adv. Mater. 2017, 29 (14), 1605884.

(10)Sales, B. C.; Mandrus, D.; Williams, R. K., Filled Skutterudite Antimonides: A New Class of Thermoelectric Materials. Science 1996, 272 (5266), 1325.

(11)Chen, L. D.; Kawahara, T.; Tang, X. F.; Goto, T.; Hirai, T.; Dyck, J. S.; Chen, W.; Uher, C., Anomalous barium filling fraction and n-type thermoelectric performance of $\mathrm{Ba}_{\mathrm{y}} \mathrm{Co}_{4} \mathrm{Sb}_{12}$. J. Appl. Phys. 2001, 90 (4), 1864-1868.

(12)Shi, X.; Kong, H.; Li, C. P.; Uher, C.; Yang, J.; Salvador, J. R.; Wang, H.; Chen, L.; Zhang, W., Low thermal conductivity and high thermoelectric figure of merit in ntype BaxYbyCo4Sb12 double-filled skutterudites. Appl. Phys. Lett. 2008, 92 (18), 182101.

(13)Shi, X.; Yang, J.; Salvador, J. R.; Chi, M.; Cho, J. Y.; Wang, H.; Bai, S.; Yang, J.; Zhang, W.; Chen, L., Multiple-Filled Skutterudites: High Thermoelectric Figure of Merit through Separately Optimizing Electrical and Thermal Transports. J. Am. Chem. Soc. 2011, 133 (20), 7837-7846.

(14)Rogl, G.; Grytsiv, A.; Rogl, P.; Peranio, N.; Bauer, E.; Zehetbauer, M.; Eibl, O., nType skutterudites $(\mathrm{R}, \mathrm{Ba}, \mathrm{Yb})_{\mathrm{y}} \mathrm{Co}_{4} \mathrm{Sb}_{12} \quad(\mathrm{R}=\mathrm{Sr}, \mathrm{La}, \mathrm{Mm}, \mathrm{DD}, \mathrm{SrMm}, \mathrm{SrDD})$ approaching $\mathrm{ZT} \approx 2.0$. Acta Mater. 2014, 63, 30-43.

(15)Zaitsev, V. K.; Fedorov, M. I.; Gurieva, E. A.; Eremin, I. S.; Konstantinov, P. P.; Samunin, A. Y.; Vedernikov, M. V., Highly effective $\mathrm{Mg}_{2} \mathrm{Si}_{1-\mathrm{x}} \mathrm{Sn}_{\mathrm{x}}$ thermoelectrics. Phys. Rev. B 2006, 74 (4), 045207.

(16)Liu, W.; Tan, X.; Yin, K.; Liu, H.; Tang, X.; Shi, J.; Zhang, Q.; Uher, C., Convergence of conduction bands as a means of enhancing thermoelectric performance of n-type $\mathrm{Mg}_{2} \mathrm{Si}_{(1-\mathrm{x})} \mathrm{Sn}_{(\mathrm{x})}$ solid solutions. Phys. Rev. Lett. 2012, 108 (16), 166601.

(17)Liu, W.; Kim, H. S.; Chen, S.; Jie, Q.; Lv, B.; Yao, M.; Ren, Z.; Opeil, C. P.; Wilson, S.; Chu, C. W.; Ren, Z., n-type thermoelectric material $\mathrm{Mg}_{2} \mathrm{Sn}_{0.75} \mathrm{Ge}_{0.25}$ for high power generation. Proc. Natl. Acad. Sci. U.S.A. 2015, 112 (11), 3269-74.

(18) Yu, C.; Zhu, T.-J.; Shi, R.-Z.; Zhang, Y.; Zhao, X.-B.; He, J., High-performance half-Heusler thermoelectric materials $\mathrm{Hf}_{1-\mathrm{x}} \mathrm{Zr}_{\mathrm{x}} \mathrm{NiSn}_{1-\mathrm{y}} \mathrm{Sb}_{\mathrm{y}}$ prepared by levitation melting and spark plasma sintering. Acta Mater. 2009, 57 (9), 2757-2764.

(19)Liu, Y.; Xie, H.; Fu, C.; Snyder, G. J.; Zhao, X.; Zhu, T., Demonstration of a phonon-glass electron-crystal strategy in (Hf,Zr)NiSn half-Heusler thermoelectric materials by alloying. J. Mater. Chem. A 2015, 3 (45), 22716-22722.

(20)Fu, C.; Bai, S.; Liu, Y.; Tang, Y.; Chen, L.; Zhao, X.; Zhu, T., Realizing high figure of merit in heavy-band p-type half-Heusler thermoelectric materials. Nat. Commun. 2015, $6(1), 8144$.

(21)Yu, B.; Zebarjadi, M.; Wang, H.; Lukas, K.; Wang, H.; Wang, D.; Opeil, C.; Dresselhaus, M.; Chen, G.; Ren, Z., Enhancement of Thermoelectric Properties by Modulation-Doping in Silicon Germanium Alloy Nanocomposites. Nano Lett. 2012, 12 (4), 2077-2082.

(22)Joshi, G.; Lee, H.; Lan, Y.; Wang, X.; Zhu, G.; Wang, D.; Gould, R. W.; Cuff, D. 
C.; Tang, M. Y.; Dresselhaus, M. S.; Chen, G.; Ren, Z., Enhanced Thermoelectric Figure-of-Merit in Nanostructured p-type Silicon Germanium Bulk Alloys. Nano Lett. 2008, 8 (12), 4670-4674.

(23)Zhao, L.-D.; Tan, G.; Hao, S.; He, J.; Pei, Y.; Chi, H.; Wang, H.; Gong, S.; Xu, H.; Dravid, V. P.; Uher, C.; Snyder, G. J.; Wolverton, C.; Kanatzidis, M. G., Ultrahigh power factor and thermoelectric performance in hole-doped single-crystal SnSe. Science 2016, 351 (6269), 141.

(24)Lee, Y. K.; Luo, Z.; Cho, S. P.; Kanatzidis, M. G.; Chung, I., Surface Oxide Removal for Polycrystalline SnSe Reveals Near-Single-Crystal Thermoelectric Performance. Joule 2019, 3 (3), 719-731.

(25)Liu, H.; Shi, X.; Xu, F.; Zhang, L.; Zhang, W.; Chen, L.; Li, Q.; Uher, C.; Day, T.; Snyder, G. J., Copper ion liquid-like thermoelectrics. Nat. Mater. 2012, 11 (5), $422-$ 425.

(26)He, Y.; Lu, P.; Shi, X.; Xu, F.; Zhang, T.; Snyder, G. J.; Uher, C.; Chen, L., Ultrahigh Thermoelectric Performance in Mosaic Crystals. Adv. Mater. 2015, 27 (24), 3639-3644.

(27)Zhao, K.; Qiu, P.; Song, Q.; Blichfeld, A. B.; Eikeland, E.; Ren, D.; Ge, B.; Iversen, B. B.; Shi, X.; Chen, L., Ultrahigh thermoelectric performance in $\mathrm{Cu}_{2-\mathrm{y}} \mathrm{Se}_{0.5} \mathrm{~S}_{0.5}$ liquidlike materials. Mater. Today Phys. 2017, 1, 14-23.

(28)Toberer, E. S.; Cox, C. A.; Brown, S. R.; Ikeda, T.; May, A. F.; Kauzlarich, S. M.; Snyder, G. J., Traversing the Metal-Insulator Transition in a Zintl Phase: Rational Enhancement of Thermoelectric Efficiency in $\mathrm{Yb}_{14} \mathrm{Mn}_{1-\mathrm{x}} \mathrm{Al}_{\mathrm{x}} \mathrm{Sb}_{11}$. Adv. Funct. Mater. 2008, 18 (18), 2795-2800.

(29) Yamada, T.; Yamane, H.; Nagai, H., A Thermoelectric Zintl Phase $\mathrm{Na}_{2+\mathrm{x}} \mathrm{Ga}_{2+\mathrm{x}} \mathrm{Sn}_{4}$ x with Disordered Na Atoms in Helical Tunnels. Adv. Mater. 2015, 27 (32), 4708-4713. (30)Wu, D.; Zhao, L.-D.; Hao, S.; Jiang, Q.; Zheng, F.; Doak, J. W.; Wu, H.; Chi, H.; Gelbstein, Y.; Uher, C.; Wolverton, C.; Kanatzidis, M.; He, J., Origin of the High Performance in GeTe-Based Thermoelectric Materials upon $\mathrm{Bi}_{2} \mathrm{Te}_{3}$ Doping. J. Am. Chem. Soc. 2014, 136 (32), 11412-11419.

(31)Rosenthal, T.; Schneider, M. N.; Stiewe, C.; Döblinger, M.; Oeckler, O., Real Structure and Thermoelectric Properties of GeTe-Rich Germanium Antimony Tellurides. Chem. Mater. 2011, 23 (19), 4349-4356.

(32)Gelbstein, Y.; Davidow, J.; Girard, S. N.; Chung, D. Y.; Kanatzidis, M., Controlling Metallurgical Phase Separation Reactions of the $\mathrm{Ge}_{0.87} \mathrm{~Pb}_{0.13} \mathrm{Te}$ Alloy for High Thermoelectric Performance. Adv. Energy Mater. 2013, 3 (6), 815-820.

(33)Li, J.; Zhang, X.; Chen, Z.; Lin, S.; Li, W.; Shen, J.; Witting, I. T.; Faghaninia, A.; Chen, Y.; Jain, A.; Chen, L.; Snyder, G. J.; Pei, Y., Low-Symmetry Rhombohedral GeTe Thermoelectrics. Joule 2018, 2 (5), 976-987.

(34)Tan, G.; Zhao, L.-D.; Shi, F.; Doak, J. W.; Lo, S.-H.; Sun, H.; Wolverton, C.; Dravid, V. P.; Uher, C.; Kanatzidis, M. G., High Thermoelectric Performance of pType SnTe via a Synergistic Band Engineering and Nanostructuring Approach. J. Am. Chem. Soc. 2014, 136 (19), 7006-7017.

(35)Zhao, L. D.; Zhang, X.; Wu, H.; Tan, G.; Pei, Y.; Xiao, Y.; Chang, C.; Wu, D.; Chi, H.; Zheng, L.; Gong, S.; Uher, C.; He, J.; Kanatzidis, M. G., Enhanced 
Thermoelectric Properties in the Counter-Doped SnTe System with Strained Endotaxial SrTe. J. Am. Chem. Soc. 2016, 138 (7), 2366-73.

(36)Li, W.; Zheng, L.; Ge, B.; Lin, S.; Zhang, X.; Chen, Z.; Chang, Y.; Pei, Y., Promoting SnTe as an Eco-Friendly Solution for p-PbTe Thermoelectric via Band Convergence and Interstitial Defects. Adv. Mater. 2017, 29 (17), 1605887.

(37)Hu, L.; Zhang, Y.; Wu, H.; Li, J.; Li, Y.; McKenna, M.; He, J.; Liu, F.; Pennycook, S. J.; Zeng, X., Entropy Engineering of SnTe: Multi-Principal-Element Alloying Leading to Ultralow Lattice Thermal Conductivity and State-of-the-Art Thermoelectric Performance. Adv. Energy Mater. 2018, 8 (29), 1802116.

(38)Luo, Y.; Cai, S.; Hao, S.; Pielnhofer, F.; Hadar, I.; Luo, Z.-Z.; Xu, J.; Wolverton, C.; Dravid, V. P.; Pfitzner, A.; Yan, Q.; Kanatzidis, M. G., High-Performance Thermoelectrics from Cellular Nanostructured $\mathrm{Sb}_{2} \mathrm{Si}_{2} \mathrm{Te}_{6}$. Joule 2020, 4 (1), 159-175.

(39)Xu, T.; Haruna, A.-Y.; Ma, Z.; Li, W.; Li, J.; Luo, Y.; Zhang, D.; Yang, J., High Power Factor and Thermoelectric Figure of Merit in Sb2Si2Te6 through Synergetic Effect of Ca Doping. Chem. Mater. 2021, 33 (20), 8097-8105.

(40)Lin, S.; Li, W.; Chen, Z.; Shen, J.; Ge, B.; Pei, Y., Tellurium as a high-performance elemental thermoelectric. Nat. Commun. 2016, 7 (1), 10287.

(41)Zeier, W. G.; Zevalkink, A.; Gibbs, Z. M.; Hautier, G.; Kanatzidis, M. G.; Snyder, G. J., Thinking Like a Chemist: Intuition in Thermoelectric Materials. Angew. Chem. Int. Ed. 2016, 55 (24), 6826-6841.

(42)Chen, Z.; Zhang, X.; Pei, Y., Manipulation of Phonon Transport in Thermoelectrics. Adv. Mater. 2018, 30 (17), 1705617.

(43)Kanatzidis, M. G., Nanostructured Thermoelectrics: The New Paradigm? Chem. Mater. 2009, 22 (3), 648-659.

(44)Hou, Z.; Xiao, Y.; Zhao, L.-D., Investigation on carrier mobility when comparing nanostructures and bands manipulation. Nanoscale 2020, 12 (24), 12741-12747.

(45)Li, J.-F.; Liu, W.-S.; Zhao, L.-D.; Zhou, M., High-performance nanostructured thermoelectric materials. NPG Asia Mater. 2010, 2 (4), 152-158.

(46)Pei, Y.; Wang, H.; Snyder, G. J., Band engineering of thermoelectric materials. Adv. Mater. 2012, 24 (46), 6125-35.

(47)Zhu, T.; Hu, L.; Zhao, X.; He, J., New insights into intrinsic point defects in $\mathrm{V}_{2} \mathrm{VI}_{3}$ thermoelectric materials. Adv. Sci. 2016, 3 (7), 1600004.

(48)Zheng, Y.; Slade, T. J.; Hu, L.; Tan, X. Y.; Luo, Y.; Luo, Z.-Z.; Xu, J.; Yan, Q.; Kanatzidis, M. G., Defect engineering in thermoelectric materials: what have we learned? Chem. Soc. Rev. 2021, 50 (16), 9022-9054.

(49)Zhang, Q.; Song, Q.; Wang, X.; Sun, J.; Zhu, Q.; Dahal, K.; Lin, X.; Cao, F.; Zhou, J.; Chen, S.; Chen, G.; Mao, J.; Ren, Z., Deep defect level engineering: a strategy of optimizing the carrier concentration for high thermoelectric performance. Energy Environ. Sci. 2018, 11 (4), 933-940.

(50)Ren, W.; Song, Q.; Zhu, H.; Mao, J.; You, L.; Gamage, G. A.; Zhou, J.; Zhou, T.; Jiang, J.; Wang, C.; Luo, J.; Wu, J.; Wang, Z.; Chen, G.; Ren, Z., Intermediate-level doping strategy to simultaneously optimize power factor and phonon thermal conductivity for improving thermoelectric figure of merit. Mater. Today Phys. 2020, 15,100250 . 
(51)Xiao, Y.; Zhao, L.-D., Seeking new, highly effective thermoelectrics. Science 2020, 367 (6483), 1196.

(52)Tan, G.; Ohta, M.; Kanatzidis, M. G., Thermoelectric power generation: from new materials to devices. Philos. Trans. R. Soc. A 2019, 377 (2152), 20180450.

(53)Liu, W.; Hu, J.; Zhang, S.; Deng, M.; Han, C.-G.; Liu, Y., New trends, strategies and opportunities in thermoelectric materials: A perspective. Mater. Today Phys. 2017, $1,50-60$.

(54)Zhang, Q. H.; Huang, X. Y.; Bai, S. Q.; Shi, X.; Uher, C.; Chen, L. D., Thermoelectric Devices for Power Generation: Recent Progress and Future Challenges Adv. Eng. Mater. 2016, 18 (2), 194-213.

(55)Luo, Z.-Z.; Zhang, X.; Hua, X.; Tan, G.; Bailey, T. P.; Xu, J.; Uher, C.; Wolverton, C.; Dravid, V. P.; Yan, Q.; Kanatzidis, M. G., High Thermoelectric Performance in Supersaturated Solid Solutions and Nanostructured n-Type PbTe-GeTe. Adv. Funct. Mater. 2018, 28 (31).

(56)Luo, Z. Z.; Cai, S.; Hao, S.; Bailey, T. P.; Su, X.; Spanopoulos, I.; Hadar, I.; Tan, G.; Luo, Y.; Xu, J.; Uher, C.; Wolverton, C.; Dravid, V. P.; Yan, Q.; Kanatzidis, M. G., High Figure of Merit in Gallium-Doped Nanostructured n-Type PbTe-xGeTe with Midgap States. J. Am. Chem. Soc. 2019, 141 (40), 16169-16177.

(57)Komisarchik, G.; Fuks, D.; Gelbstein, Y., High thermoelectric potential of n-type $\mathrm{Pb}_{1-\mathrm{x}} \mathrm{Ti}_{\mathrm{x}} \mathrm{Te}$ alloys. J. Appl. Phys. 2016, 120 (5), 055104.

(58)Jood, P.; Ohta, M.; Kunii, M.; Hu, X.; Nishiate, H.; Yamamoto, A.; Kanatzidis, M. G., Enhanced average thermoelectric figure of merit of n-type $\mathrm{PbTe}_{1-\mathrm{x}} \mathrm{I}_{\mathrm{x}}-\mathrm{MgTe} . J$. Mater. Chem. C. 2015, 3 (40), 10401-10408.

(59)Zhang, Q.; Chere, E. K.; Wang, Y.; Kim, H. S.; He, R.; Cao, F.; Dahal, K.; Broido, D.; Chen, G.; Ren, Z., High thermoelectric performance of n-type $\mathrm{PbTe}_{1-\mathrm{y}} \mathrm{S}_{\mathrm{y}}$ due to deep lying states induced by indium doping and spinodal decomposition. Nano Energy 2016, 22, 572-582.

(60)Xiao, Y.; Wang, D.; Qin, B.; Wang, J.; Wang, G.; Zhao, L.-D., Approaching Topological Insulating States Leads to High Thermoelectric Performance in n-Type PbTe. J. Am. Chem. Soc. 2018, 140 (40), 13097-13102.

(61)Wang, D.; Qin, Y.; Wang, S.; Qiu, Y.; Ren, D.; Xiao, Y.; Zhao, L.-D., Synergistically Enhancing Thermoelectric Performance of n-Type PbTe with Indium Doping and Sulfur Alloying. Ann. Phys. 2020, 532 (11), 1900421.

(62)Zhang, J.; Wu, D.; He, D.; Feng, D.; Yin, M.; Qin, X.; He, J., Extraordinary Thermoelectric Performance Realized in n-Type PbTe through Multiphase Nanostructure Engineering. Adv. Mater. 2017, 29 (39), 1703148.

(63)Wang, S.; Xiao, Y.; Chen, Y.; Peng, S.; Wang, D.; Hong, T.; Yang, Z.; Sun, Y.; Gao, X.; Zhao, L.-D., Hierarchical structures lead to high thermoelectric performance in $\mathrm{Cu}_{\mathrm{m}+\mathrm{n}} \mathrm{Pb}_{100} \mathrm{Sb}_{\mathrm{m}} \mathrm{Te}_{100} \mathrm{Se}_{2 \mathrm{~m}}$ (CLAST). Energy Environ. Sci. 2021, 14 (1), 451-461.

(64)Tan, G.; Stoumpos, C. C.; Wang, S.; Bailey, T. P.; Zhao, L.-D.; Uher, C.; Kanatzidis, M. G., Subtle Roles of Sb and S in Regulating the Thermoelectric Properties of N-Type PbTe to High Performance. Adv. Energy Mater. 2017, 7 (18), 1700099.

(65)Xiao, Y.; Wu, Y.; Nan, P.; Dong, H.; Chen, Z.; Chen, Z.; Gu, H.; Ge, B.; Li, W.; Pei, Y., $\mathrm{Cu}$ Interstitials Enable Carriers and Dislocations for Thermoelectric 
Enhancements in $\mathrm{n}-\mathrm{Pb}_{\mathrm{Te} 0.75} \mathrm{Se}_{0.25}$. Chem 2020, 6 (2), 523-537.

(66)Qin, B.; Hu, X.; Zhang, Y.; Wu, H.; Pennycook, S. J.; Zhao, L.-D., Comprehensive Investigation on the Thermoelectric Properties of p-Type PbTe-PbSe-PbS Alloys. $A d v$. Electron. Mater. 2019, 5 (12), 1900609.

(67)Pei, Y.; Tan, G.; Feng, D.; Zheng, L.; Tan, Q.; Xie, X.; Gong, S.; Chen, Y.; Li, J.F.; He, J.; Kanatzidis, M. G.; Zhao, L.-D., Integrating Band Structure Engineering with All-Scale Hierarchical Structuring for High Thermoelectric Performance in PbTe System. Adv. Energy Mater. 2017, 7 (3), 1601450.

(68)Wu, Y.; Nan, P.; Chen, Z.; Zeng, Z.; Liu, R.; Dong, H.; Xie, L.; Xiao, Y.; Chen, Z.; Gu, H.; Li, W.; Chen, Y.; Ge, B.; Pei, Y., Thermoelectric Enhancements in PbTe Alloys Due to Dislocation-Induced Strains and Converged Bands. Adv. Sci. 2020, 7 (12), 1902628.

(69)Rowe, D. M., CRC Handbook of Thermoelectrics. CRC Press: 1995.

(70)Jia, N.; Cao, J.; Tan, X. Y.; Dong, J.; Liu, H.; Tan, C. K. I.; Xu, J.; Yan, Q.; Loh, X. J.; Suwardi, A., Thermoelectric materials and transport physics. Mater. Today Phys. 2021, 21, 100519.

(71)Zhang, J.; Liu, R.; Cheng, N.; Zhang, Y.; Yang, J.; Uher, C.; Shi, X.; Chen, L.; Zhang, W., High-Performance Pseudocubic Thermoelectric Materials from Non-cubic Chalcopyrite Compounds. Adv. Mater. 2014, 26 (23), 3848-3853.

(72)Zhao, L.-D.; Wu, H.; Hao, S.; Wu, C.-I.; Zhou, X.; Biswas, K.; He, J.; Hogan, T. P.; Uher, C.; Wolverton, C., All-scale hierarchical thermoelectrics: MgTe in PbTe facilitates valence band convergence and suppresses bipolar thermal transport for high performance. Energy Environ. Sci. 2013, 6 (11), 3346-3355.

(73)Pei, Y.; Wang, H.; Gibbs, Z. M.; LaLonde, A. D.; Snyder, G. J., Thermopower enhancement in $\mathrm{Pb} 1-\mathrm{x} \mathrm{Mn} \times \mathrm{Te}$ alloys and its effect on thermoelectric efficiency. NPG Asia Mater. 2012, 4 (9), e28-e28.

(74)Witting, I. T.; Grovogui, J. A.; Dravid, V. P.; Snyder, G. J., Thermoelectric transport enhancement of Te-rich bismuth antimony telluride $\left(\mathrm{Bi}_{0.5} \mathrm{Sb}_{1.5} \mathrm{Te}_{3+\mathrm{x}}\right)$ through controlled porosity. J. Materiomics 2020, 6(3): 532-544.

(75)Zevalkink, A.; Smiadak, D. M.; Blackburn, J. L.; Ferguson, A. J.; Chabinyc, M. L.; Delaire, O.; Wang, J.; Kovnir, K.; Martin, J.; Schelhas, L. T.; Sparks, T. D.; Kang, S. D.; Dylla, M. T.; Snyder, G. J.; Ortiz, B. R.; Toberer, E. S., A practical field guide to thermoelectrics: Fundamentals, synthesis, and characterization. Appl. Phys. Rev. 2018, 5 (2), 021303.

(76)Ma, Z.; Wei, J.; Song, P.; Zhang, M.; Yang, L.; Ma, J.; Liu, W.; Yang, F.; Wang, $\mathrm{X}$., Review of experimental approaches for improving zT of thermoelectric materials. Mater. Sci. Semicond. Process. 2021, 121, 105303.

(77)Li, J.; Pan, Y.; Wu, C.; Sun, F.; Wei, T., Processing of advanced thermoelectric materials. Sci. China Technol. Sci. 2017, 60 (9), 1347-1364. 